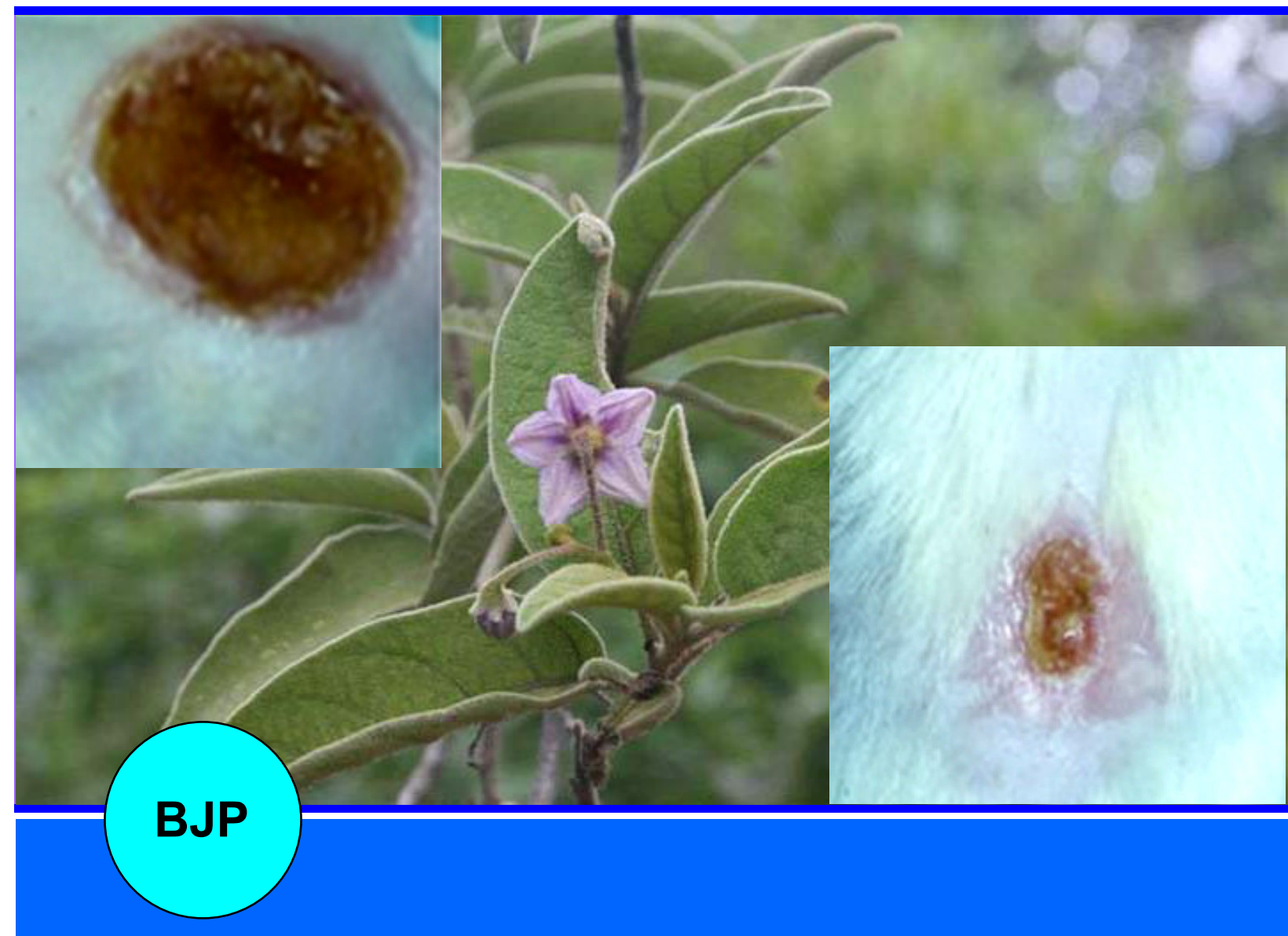

Bangladesh Journal of Pharmacology

Research Article

Solanum incanum extract enhances wound healing and tissue regeneration in burn mice model 


\title{
Solanum incanum extract enhances wound healing and tissue regeneration in burn mice model
}

\author{
Zainab Qureshi', Taous Khan', Abdul Jabbar Shah'1 and Fazli Wahid²
}

${ }^{1}$ Department of Pharmacy, COMSATS University Islamabad, Abbottabad Campus 22060, Pakistan; ${ }^{2}$ Biotechnology Program, Department of Environmental Sciences, COMSATS University Islamabad, Abbottabad Campus 22060,

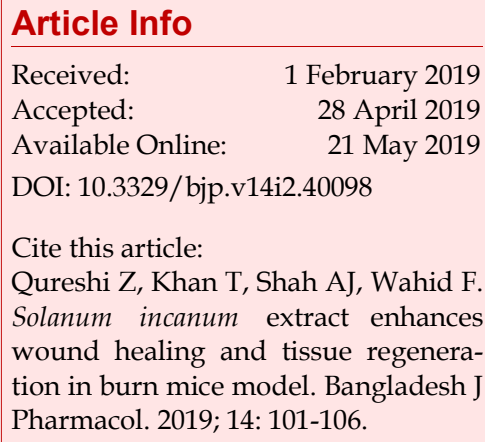

\section{Abstract}

This study was conducted to evaluate the topical efficacy of Solanum incanum for the treatment of partial-thickness burn in mice model. Mice were treated with topical ointment of $S$. incanum three times daily for 14 days. The wound healing was observed through wound contraction and histological parameters. The group treated with $S$. incanum ointment showed $81 \%$ reduction in wound area as compared to negative control where wound area reduced to $22 \%$. The histological analysis further confirmed that ointment favors the tissue regeneration and reepithelization thus heal wound rapidly as compared to other groups. In conclusion, S. incanum extract enhances wound healing and tissue regeneration.

\section{Introduction}

Burn is known as one of the most destructive forms of injury with a vast spectrum of consequences. Despite the discovery of various antibacterial and antiseptic agents, burn wound healing is still a challenging health issue in modern medicine. Because of economic constraints and limited resources for the import of appropriate treatments, the health authorities are obliged to rely on traditional herbal remedies.

The care of wound be delineated to the ancient civilization that was based upon herbs. It has been reported that about $1 / 3 \mathrm{rd}$ of all herbal medicines in use are for the treatment of skin disorders and wounds (Mantle et al., 2001). Various plants such as Allium sativum (Farahpour et al., 2017), Aloe vera (Maenthaisong et al., 2007), Carica papaya (Gurung and SkalkoBasnet et al., 2009), Centaurea pterocaula (Ötün and Yücel, 2019), Iris forentina (Mirmalek et al., 2015), Otostegia persica (Ganjali et al., 2013), Pistacia lentiscus (Djerrou et al., 2010) have been investigated for the treatment of burn.
Solanum incanum (family: Solanaceae), with a common name of bitter apple and thorn apple, is a herb belongs to the family Solanaceae. Different parts of it have various ethnopharmacological uses such as decoction of root and leaf possess analgesic properties while root infusions, leaf paste and pounded fruits are used for scarifications. Leaf sap have uses in washing of painful areas. Root infusion is used as mouth wash for relief of toothache (Amadi et al., 2010). Various parts of the plant are also broadly used in the treatment of skin problems, including skin infections, whitlow, burns, sores, ringworm, warts, rashes, wounds, carbuncles, ulcers and benign tumors. Khyber Pakhtunkhwa and Northern areas of Pakistan are bestowed with unique biodiversity and are rich in medicinal herbs which have wound healing properties, but no scientific research has been carried out on majority of these plants.

It has been found that $S$. incanum have well reported wound healing properties in folk medicine but have never been scientifically evaluated (Ali and Qaiser, 2009). Therefore, the current study was carried out to investigate the healing and tissue regeneration potential 
of S. incanum for deep partial-thickness burn wounds.

\section{Materials and Methods \\ Collection and identification of S. incanum}

The fresh leaves of S. incanum were collected from the District Abbottabad. Dr. Abdul Nazir, Department of Environmental Sciences CUI, Abbottabad Campus authenticated the plant material. The voucher specimen of plant (DB-GC (SIS)-0028) was deposited at the Department of Botany, Government Postgraduate College Abbottabad.

\section{Processing and extraction}

Leaves of the plant were shed-dried for 14 days at room temperature $\left(20-25^{\circ} \mathrm{C}\right)$. The dried leaves were coarsely powdered in a grinder and was subjected for extraction by macerating $250 \mathrm{~g}$ of dried powder in $1.5 \mathrm{~L}$ of $70 \%$ methanol. A stainless steel stirrer was used to mix the extract. After 14 days, the extract was filtered initially through porcelain cloth and then with Whatman filter paper No. $42(125 \mathrm{~mm})$ and was concentrated using vacuum rotary evaporator (Yamato Rotary Evaporator, Model RE 801, Korea). The final percentage yield was $15 \% \mathrm{w} / \mathrm{w}$.

\section{Preparation of ointment}

Ointment $1 \%(\mathrm{w} / \mathrm{w})$ was prepared using petroleum jelly as a base (vaseline) obtained from the Shaheen Chemist, Abbottabad. Petroleum jelly was melted on hot plate at $37^{\circ} \mathrm{C}$ and mixed with methanolic extract of $S$. incanum under continuous stirring.

\section{Animals and burn model}

Balb/c male mice (30-35 g) were used as an animal model. The mice were purchased from the National

\section{Box 1: Induction of deep partial-thickness burn}

\section{Principle}

The deep partial-thickness burn (damage of deep dermis; burn appears pale than red) was induced using a specially designed metal rod. It is evaluated by macroscopic and microscopic changes.

\section{Requirements}

Electric clippers; ethanol $(70 \%)$, ketamine, metal rod $(1.7 \mathrm{~cm}$ diameter), mouse, syringe, xylazine, xylocaine

\section{Procedure}

Step 1: Each mouse was acclimatized to laboratory condition for one week prior to the experiment

Step 2: Each mouse was weight and anesthetized using the combination of ketamine $(75 \mathrm{mg} / \mathrm{kg})$ and xylazine $(1.5 \mathrm{mg} /$ $\mathrm{kg}$ ) via intraperitoneal injection

Step 3: The hair from the dorsal side of the anesthetized
Institute of Health, Islamabad. They were kept in standard conditions $\left(25 \pm 2{ }^{\circ} \mathrm{C}, 12\right.$ hours light and dark cycle) with free access to food and water at animal house of COMSATS University Islamabad, Abbottabad Campus. All animals were kept for acclimatization, one week prior to the experiment.

\section{Treatment}

The mice were divided into four groups according to the treatment protocol with a minimum of five animals in each group. The treatment was started after 12 hours of wound induction. The first group received topical treatment of S. incanum (1\%) ointment. Second group was kept as vehicle control and treated with petroleum jelly. Third group was positive control given topical treatment of silver sulfadiazine with a brand name Quench (silver sulfadiazine) cream made by the Ferozsons Laboratories Ltd, Pakistan. The fourth group was kept as negative control and given no treatment. All the treatments including S. incanum (1\%) ointment, petroleum jelly and ointments were performed topically three times a day at 8 hours interval for consecutive 14 days.

\section{Assessment of burn wounds}

The wound healing was monitored through physical parameter by measuring the wound area with a ruler scale on day $0,4,8,12$ and 14 . The contraction of wound was measured by estimating the decrease in wound area as compared to initial wound by using below formula:

Percent healing $=1-$ Wound area on particular day $/$ Wound area on day $0 \times 100$

Moreover, digital photography was used as a quantitative method for estimating the changes and closure of wound. For this purpose, digital camera (DSC-W70, mouse was shaved using electric clippers

Step 4: The area was sterile with $70 \%$ ethanol prior to wound infliction

Step 5: In order to induce deep partial-thickness burn, the rod was heated on open flame for $5 \mathrm{~min}$ and placed on the selected area for $9 \mathrm{sec}$

Step 6: Xylocaine gel was used as local anesthetic and pain killer and applied immediately after wound induction

Step 7: Each animal was housed in separate cage

Notes

Mouse was used as animal model. Other animals like rat, rabbit or pig may be used. Temperature, duration and contact pressure are the factors that are important to achieve uniform burn.

\section{References}

Guo et al., 2017 
Sony, Japan) was used along with a lamp as additional light source. Photographs were taken on regular intervals at day $0,4,8,12$ and 14 .

\section{Histopathology}

On the last day of experiment (day 14 of treatment), mice were sacrificed with cervical dislocation. The wound area of each animal was excised and fixed with $10 \%$ formalin. The paraffin embedded tissues were cut with microtome and stained with hematoxylin and eosin (H \& E) dye. The slides were observed under light microscopy and photographs were also taken under low and high magnifications.

\section{Statistical analysis}

Wherever applicable, the statistical analysis was performed using Student's t-test by GraphPad prism version 5 software. The data given are expressed as \pm standard error means (SEM). $\mathrm{p} \leq 0.05$ was considered statistically significant.

\section{Results}

\section{Wound healing and photographic analysis}

The data for wound contraction has been given in Table I. It was observed that at first day the wound size was similar in all groups. The wound size started reducing in S. incanum-treated group from day 4 and continued till day 14 . No significant reduction in wound size was shown by vehicle and negative control group. The positive group showed similar trend as of S. incanum but, the wound contraction was slightly better in positive group. On the last day of experiment, $S$. incanum-treated group showed $81 \%$ percent healing in comparison with 23, 22 and $84 \%$ for vehicle, negative control and positive control, respectively. The abovementioned results were further supported by photographs taken at different days (Figure 1). It can also be seen in these photographs that contraction started on 4 th day and maximum wound closure was observed on the last day of experiment in S. incanum-treated and positive control group.

\section{Tissue regeneration analysis}

Histopathology was performed in order to access the reepithelization, tissue regeneration and signs of inflammation after burn damage. It was observed under low power resolution that in S. incanum treated group the wounded area was covered by new epithelium with a healthy granulation tissue below (Figure 2). In comparison, the vehicle group was still in inflammatory phase and necrotic tissue can prominently be seen in negative control group with no obvious sign of healing (Figure 2). The positive group showed similar results to that of $S$. incanum treated group and smooth healing pattern can be observed.

\section{Discussion}

Present study focuses on the scientific evaluation of wound healing potential of $S$. incanum for burn wounds. S. incanum is well known medicinal plant for its antimicrobial activities as several scientific studies have demonstrated its efficacy against different microbial strains, however, wound healing activity of this plant is not documented so far (Kipngeno et al., 2014). The use of various medicinal plants for treating skin disorders and cutaneous wounds is scientifically proven from different studies (Rashed et al., 2003). The complex process of wound healing and tissue repair involves a cascade of events starts from the moment of injury and continue for varying periods of time depending on the type of wound and extent of damage (Varga et al., 1987). The adequate burn wound management is required for timely progression of healing process so that damaged tissue can be repaired (Quaglino et al., 1990) and its anatomical and physiological functions could be restored.

The wound healing potency of various herbal extracts is attributed to free radical-scavenging action. The quicker process of wound healing could be a function of either the individual or the synergistic effects of these bioactive molecules (Okoli et al., 2007). The results of the wound healing activity of this study reveals that the pattern of wound contraction among $S$. incanum treated group was quite prominent and faster as compared to vehicle and negative control group. The wound contraction efficacy of $S$. incanum was found to be very close to the positive control group. The percent wound

Table I

\begin{tabular}{|c|c|c|c|c|c|c|}
\hline \multirow[t]{2}{*}{ Treatment groups } & Day 0 & Day 4 & Day 8 & Day 12 & Day 14 & \multirow{2}{*}{$\begin{array}{l}\text { Percent healing } \\
\text { (Day 14) }\end{array}$} \\
\hline & \multicolumn{5}{|c|}{ Wound diameter $\left(\mathrm{mm}^{2}\right)$} & \\
\hline Vehicle & $255.0 \pm 0.0$ & $245.8 \pm 8.1$ & $229.6 \pm 23.9$ & $214.0 \pm 34.2$ & $196.6 \pm 32.7$ & 23 \\
\hline Negative control & $255.0 \pm 0.0$ & $250.0 \pm 4.6$ & $233.6 \pm 21.8$ & $210.6 \pm 25.3$ & $200.2 \pm 31.4$ & 22 \\
\hline S. incanum & $255.0 \pm 0.0$ & $181.0 \pm 10.4$ & $143.6 \pm 7.7$ & $77.6 \pm 13.9$ & $49.2 \pm 11.1$ & 81 \\
\hline Positive control & $255.0 \pm 0.0$ & $173.8 \pm 6.7$ & $129.8 \pm 5.3$ & $79.4 \pm 8.6$ & $42.2 \pm 6.1$ & 84 \\
\hline
\end{tabular}




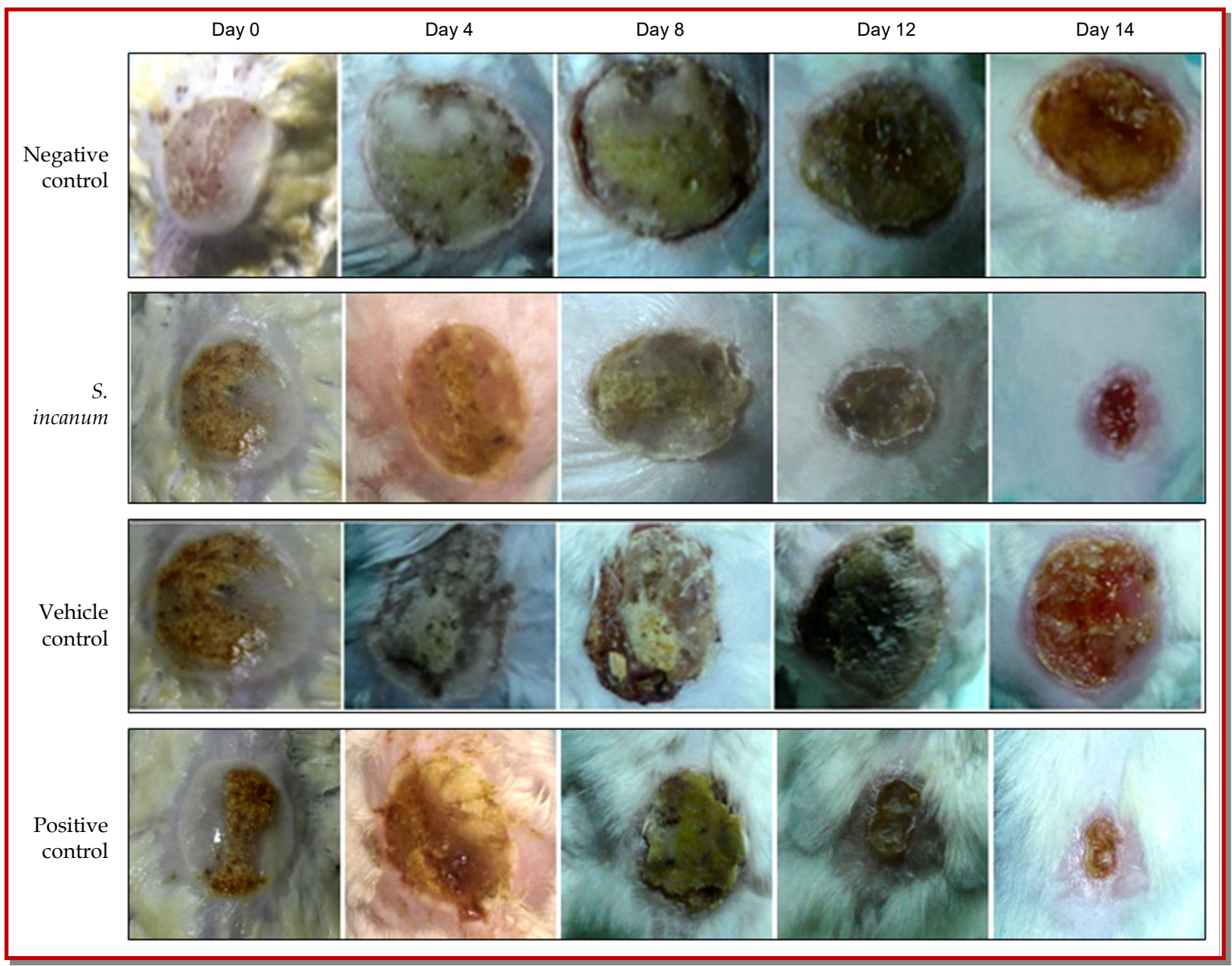

Figure 1: Photographic analysis of wound healing on different days of treatment in negative control, S. incanum, vehicle and positive control group

healing of S. incanum (81\%) was also far better in comparison to vehicle treated group $(23 \%)$. These results can be supported by the fact that faster closure of wound indicated the better efficacy of medication (Demilew et al., 2018). Previous studies reveals that the active agents in herbal extracts such as triterpenes, alkaloids, flavonoids, tannins, saponins, anthraquinones, and secondary metabolites have role in promoting the healing process (Chaudhari and Mengi, 2006). These agents usually influence one or more phases of the healing process (Karodi et al., 2009). Especially, tannins and flavonoids have the wound healing capability as it have free radical scavenging and anti-oxidant property which ultimately reduce lipid peroxidation, thereby decreasing cell necrosis and improving vascularity (Baravkar et al., 2008). S. incanum contains both tannins and flavonoids so it may have the wound healing activity through above mentioned process, however further studies are needed to confirm $S$. incanum wound healing mechanism.

Histological analysis is a powerful method to monitor healing and regeneration at tissue level. In Figure 2, microphotographs clearly showed that wound bed in $S$. incanum treated group is covered by new epithelial layer and tissue regeneration can also be observed. Epidermis being the outermost layer of the skin act as a physical barrier. Burn damages the epidermis which is restored by the process of re-epithelialization in which keratinocytes migrate from the lower skin layers and differentiate into mature cells covering the wound bed (Panchatcharam et al., 2006). Moreover, healthy granulation tissue, sebaceous glands and new blood vessels are the signs of proper wound healing. The histological analysis showed re-ephithilization, healthy granulated tissue, regenerated sebaceous glands and new blood vessels in $S$. incanum treated group. This shows that $S$. incanum treatment promotes migration and differentiation of keratinocytes, formation of new connective tissue and microscopic blood vessels which are characteristics of healthy granulated tissues. S. incanum showed best healing pattern among all the groups closer to positive control. Whereas, vehicle and negative control group had clear signs of inflammation with no tissue regeneration. 


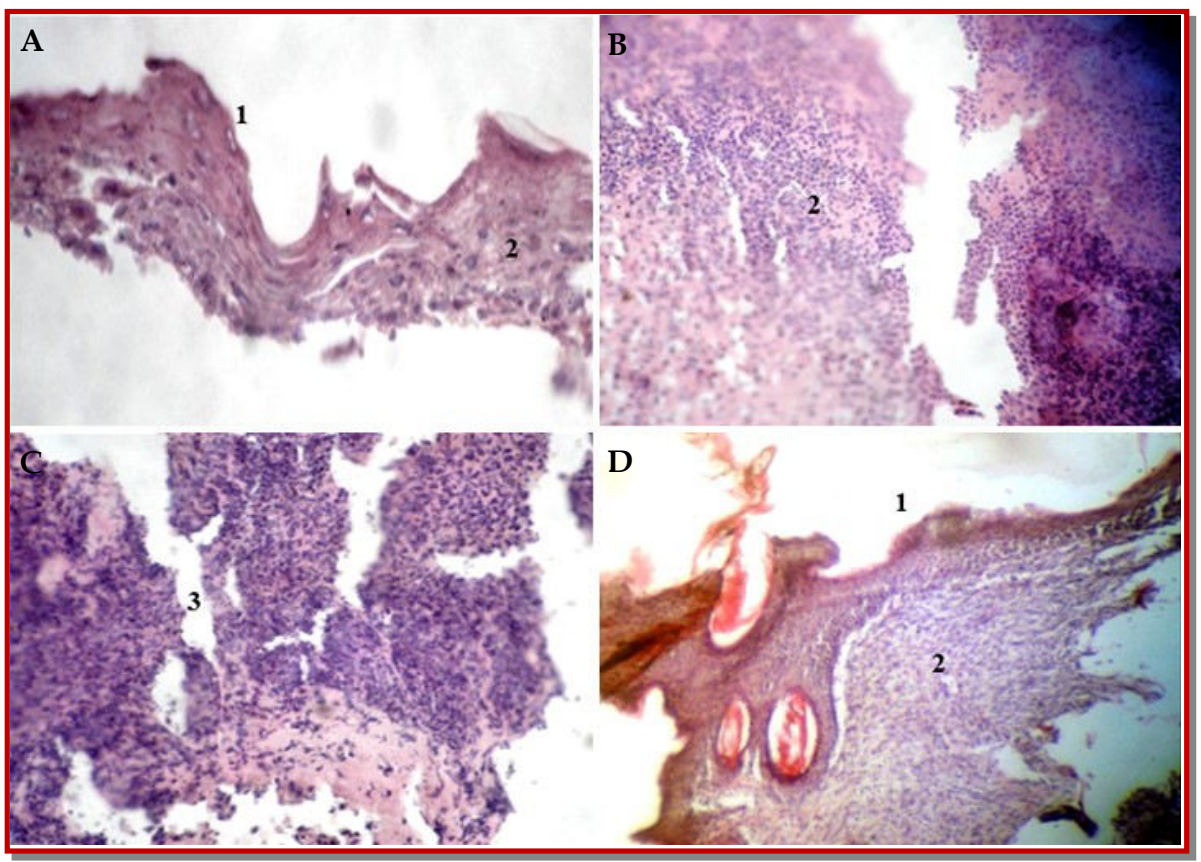

Figure 2: (A) Histopathology of S. incanum treated group showing intact epidermis and tissue regeneration. (B) Vehicle control showing ulceration and inflammation indicated by neutrophils. (C) Negative control showing central inflammation. (D) Positive control showing intact epidermis and tissue regeneration; 1 . Regenerated epidermis 2 . Granulation tissue 3 . Necrotic tissue and inflammation

\section{Conclusion}

The photographic and histopathological analysis clearly demonstrated that S. incanum ointment stimulated wound healing at cell and tissue level.

\section{Ethical Issue}

All the experimental procedures and protocols involving animals were approved by the CUI Ethical Committee and were in accordance with the guidelines of institute of laboratory animal Resources, Commission on Life Sciences, National Research Council (NRC, 1996).

\section{Conflict of Interest}

There is no conflict of interests.

\section{References}

Ali H, Qaiser M. The ethnobotany of Chitral valley, Pakistan with particular reference to medicinal plants. Pakistan J Bot. 2009; 41: 2009-41.

Amadi JE, Salami SO, Eze CS. Antifungal properties and phytochemical screening of extracts of African basil (Ocimum gratissimum L.). Agric Biol J N Am. 2010; 2: 163-66.

Baravkar AA, Kale RN, Patil RN, Sawant SD. Pharmaceutical and biological evaluation of formulated cream of methanolic extract of Acacia nilotica leaves. Res J Pharm Technol. 2008: 1: $480-83$.
Chaudhari M, Mengi S. Evaluation of phytoconstituents of Terminalia arjuna for wound healing activity in rats. Phytother Res. 2006; 20: 799-805.

Demilew W, Adinew GM, Asrade S. Evaluation of the wound healing activity of the crude extract of leaves of Acanthus polystachyus Delile (Acanthaceae). Evid Based Complement Alternat Med. 2018; 2018.

Djerrou Z, Maameri Z, Hamdi-Pacha Y, Serakta M, Riachi F, Djaalab H, Boukeloua A. Effect of virgin fatty oil of Pistacia lentiscus on experimental burn wound's healing in rabbits. Afr J Tradit Complement Altern Med. 2010; 7: 258-63.

Farahpour MR, Hesaraki S, Faraji D, Zeinalpour R, Aghaei M. Hydroethanolic Allium sativum extract accelerates excision wound healing: Evidence for roles of mast-cell infiltration and intracytoplasmic carbohydrate ratio. Brazilian J Pharm Sci. 2017; 53: e15079.

Guo HF, Ali RM, Hamid RA, Zaini AA, Khaza'ai H. A new model for studying deep partial-thickness burns in rats. Int J Burns Trauma. 2017; 7: 107-14.

Gurung S, Skalko-Basnet N. Wound healing properties of Carica papaya latex: In vivo evaluation in mice burn model. J Ethnopharmacol. 2009; 121: 338-41.

Karodi R, Jadhav M, Rub R, Bafna A. Evaluation of the wound healing activity of a crude extract of Rubia cordifolia L. (Indian madder) in mice. Int J Appl Res Nat Prod. 2009; 2: 12 -18 .

Kipngeno CD, Mshimba SM, Gilbert C. Antimicrobial activity and phytochemical investigation of crude extracts of the fruits of Solanum incanum (Solananceae) and Dovyalis abbysinica (Flacourtiaceae). Sci J Microbiol. 2014; 2014.

Maenthaisong R, Chaiyakunapruk N, Niruntraporn S, Kong- 
kaew C. The efficacy of Aloe vera used for burn wound healing: A systematic review. Burns 2007; 33: 713-18.

Mantle D, Gok MA, Lennard TW. Adverse and beneficial effects of plant extracts on skin and skin disorders. Adverse Drug React Toxicol Rev. 2001; 20: 89-103.

Mirmalek SA, Parsa T, Parsa Y, Yadollah-Damavandi S, SalimiTabatabaee SA, Jangholi E, Hosseini S, Ashkani-Esfahani S, Abooghadareh $\mathrm{H}$, Haghighifard E. The wound healing effect of Iris forentina on full thickness excisional skin wounds: A histomorphometrical study. Bangladesh J Pharmacol. 2015; 11: 86-90.

Okoli CO, Akah, PA, Nwafor SV, Anisiobi, AI, Ibegbunam IN, Erojikwe O. Anti-inflammatory activity of hexane leaf extract of Aspilia africana CD Adams. J Ethnopharmacol. 2007; 109: 219-25.

Ötün B, Yücel U. Wound healing effect of different extracts of Centaurea pterocaula. Bangladesh J Pharmacol. 2019; 14: 9-6.
Panchatcharam M, Miriyala S, Gayathri VS, Suguna L. Curcumin improves wound healing by modulating collagen and decreasing reactive oxygen species. Mol Cell Biochem. 2006; 290: 87-96.

Quaglino D Jr, Nanney LB, Kennedy R, Davidson JM. Transforming growth factor-beta stimulates wound healing and modulates extracellular matrix gene expression in pig skin. I. Excisional wound model. Lab Invest J Technical Methods Pathol. 1990; 63: 307-19.

Rashed AN, Afifi FU, Disi AM. Simple evaluation of the wound healing activity of a crude extract of Portulaca oleracea L. (growing in Jordan) in Mus musculus JVI-1. J Ethnopharmacol. 2003; 88: 131-36.

Varga J, Rosenbloom J, Jimenez SA. Transforming growth factor $\beta$ (TGF $\beta$ ) causes a persistent increase in steady-state amounts of type I and III collagen and fibronectin mRNAs in normal human dermal fibroblasts. Biochem J. 1987; 247: 597604. 